[Agr. Biol. Chem., Vol. 29, No. 5, p. 403 406, 1965]

\title{
Uptake of Homologous Series of $p$-n-Alkylphenols by Phytopathogenic Fungi
}

\author{
By Yasuhiko Uesugr and Toshinobu Murai* \\ Laboratory of Pesticides, The Institute of Physical and Chemical Research, Tokyo \\ and *Division of Agricultural Chemicals, National Institute \\ of Agricultural Sciences, Tokyo \\ Received November 12, 1964
}

\begin{abstract}
Uptake of homologous series of $p$ - $n$-alkylphenols by fungi from aqueous phase was studied using spores of Piricularia oryzae and Gibberella fujikuroi, and mycelia of $P$. oryzae as test organisms.

Process of uptake seemed to be physical, because dead cells took up as much phenol as did living cells. Amount of phenol taken up by fungal cells equilibrated with concentration of remaining phenol in external aqueous phase. Uptake was found to increase with increasing alkyl side chain length, and solubility of the homologous series decreases at higher rate than uptake increases. Uptake of higher homologue is not supposed to reach the level enough to inhibit growth of fungi, on account of its slight solubility.

These results explain the reason why antifungal activity of $p$ - $n$-alkylphenol increases with increasing alkyl chain length up to a certain homologue, and decreases for the higher members.
\end{abstract}

Preceding papers ${ }^{1,2)}$ have reported that antifungal activity of homologous series of $0^{-}$and $p$-alkylphenols and several series of alkylchlorophenols against phytopathogenic fungi increases with increasing length of alkyl chain up to a certain homologue, and decreases for the higher members. The first step of fungicidal action of most of fungicides is contact of fungicide with fungal cells, followed by accumulation of fungicide in and on the cells. This step is often said to be important for fungicidal action. ${ }^{3 \sim 5}$ ?

Fungicidal action of alkylated phenols has been further investigated, in special regard with this step of fungicidal action, using homologous series of $p$ - $n$-alkylphenols as test fungicides.

1) Y. Uesugi and T. Suzuki, Bull. Nat. Inst. Agr. Sci., Cl7, 181 (1964).

2) Y. Uesugi and T. Suzuki ibid., C17, 193 (1964).

3) S. Rich and J. G. Horsfall, Phytopathology, 39, 19 (1949).

4) R.G. Ross and R. A. Ludwig, Can J. Botany, 35, 65 (1957).

5) E. Somers. ibid., 36, 997 (1958).

\section{MATERIALS AND METHODS}

\section{Fungi}

Spores of Piricularia oryzae and Gibberella fujikuroi, and mycelia of $P$. oryzae were used.

Spores were obtained as previously reported, 11 washed with water, centrifuged, and resuspended in M/15 phosphate buffer, $\mathrm{pH} 7.0$. Quantity of spores in this suspension was counted with a Thoma haemocytometer.

Mycelia of $P$. oryzae were obtained from shaking culture in liquid medium (containing $20 \mathrm{~g}$ glucose, $5 \mathrm{~g}$ yeast extract and decoction of $20 \mathrm{~g}$ rice straw per 11 ) for four days at $27 \sim 28^{\circ} \mathrm{C}$, filtered, washed with water, and used for the test. Tested mycelia were weighed after drying for eight hours at $105 \sim 110^{\circ} \mathrm{C}$.

\section{Fungicides}

Preparation, physical constant, and antifungal activity of $p$ - $n$-alkylphenols were reported in the previous paper.17 Solubility of the chemicals in water at $27.5^{\circ} \mathrm{C}$ was illustrated in Fig. 5.

\section{Determination of Uptake of Fungicides by Fungi}

Uptake of alkylphenol by fungi was measured by decrease in concentration of the phenol in external solution, as follows: 
Spore suspension or mycelia were added to aqueous solution of $p$-n-alkylphenol buffered with phosphates (the final concentration of which was $\mathrm{M} / 15$ ) at $\mathrm{pH}$ 7.0. The suspension was agitated and kept at $27.5^{\circ} \mathrm{C}$ over a fixed period. After centrifugation, $p$ - $n$-alkylphenol in an aliquot of the supernatant was extracted by a certain volume of chloroform. Absorbancy of the chloroform solution at $278.5 \mathrm{~m} \mu$ was determined.

The same procedure was conducted without fungi, and without fungicide. Uptake was calculated from absorbancies obtained from the test on the fungicide uptake by fungus $(A)$, from blank tests without fungi $(B)$, and without fungicide $(C)$, as follows:

$$
B-(A-C) \times K
$$

where $K$ is a factor given by calibration curve.

\section{EXPERIMENTAL RESULTS}

\section{Rate of Uptake}

Uptake rate of $p-n$-alkylphenol by spores of G. fujikuroi with increase in time of treatment is shown in Fig. 1.

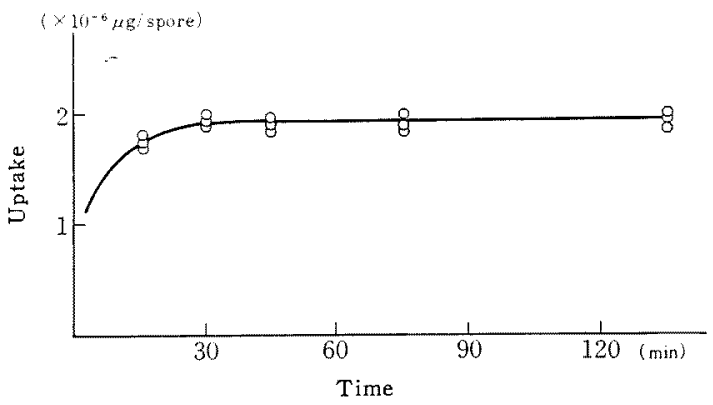

FIG. 1. Rate of Uptake of p-Hexylphenol by Spore of $G$. fujikuroi

Initial concentration of $p$-hexylphenol $=27.4 \cdot \mathrm{g} / \mathrm{m} 1$ Quantity of spores $=4.3 \times 10^{6}$ spores $/ \mathrm{ml}$.

The same mode of uptake-time curve was obtained by spores and mycelia of $P$. oryzae. Because the uptake-time curves indicate that the uptake was accomplished during thirty minutes, and did not vary at least for two hours, sixty minutes were chosen as time of treatment for all the experiments.

\section{Uptake by Dead Cells}

Uptake by dead cells (treated as stated in Table 1) was determined in order to know whether the uptake is dependent on cell
TABLE I. UPTAKE OF $p$-HEXYLPHENOL BY $P$. oryzae AFTER VARIOUS TREATMENTS

$\begin{array}{cc}\text { uptake by } & \text { uptake by } \\ \text { spores* } & \text { mycelia** }\end{array}$

boiling for $5 \mathrm{~min}$.

in $M / 15$ phosphate $\times 10^{-6} \mu \mathrm{g} / \mathrm{spore} \mu \mathrm{g} / \mathrm{mg}$ dry weight

buffer, $\mathrm{pH} 7.0$

10.7

3.7

$0.1 \% \mathrm{HgCl}_{2}$ for $5 \mathrm{~min}$. 9.1

3.1

$95 \%$ ethanol for $5 \mathrm{~min}$. 6.6

2.8

control

10.3

3.1

* Initial concentrations of $p$-hexylphenol and spores were $20.6 \mu \mathrm{g} / \mathrm{ml}$ and $0.6 \times 10^{6}$ spores $/ \mathrm{ml}$, respectively.

** Initial concentrations of $p$-hexylphenol and mycelia were $28.3 \mu \mathrm{g} / \mathrm{ml}$ and $25 \mathrm{mg}$ fresh weight $/ \mathrm{ml}$ (ca. $3 \mathrm{mg}$ dry weight, $\mathrm{ml}$ ), respectively.

metabolism or governed merely by physical process.

The result shows that uptake by dead cells was nearly equal to that by living cells, seemingly governed by physical process (Table I). Some diminution of uptake by ethanol treated spores observed in this experiment may be caused by some change in physical conditions of fungi, for instance, release of lipoidal fraction from fungi.

Relationship between Uptake and Concentration in External Solution

Relationship between uptake of $t$-n-alkylphenol and concentration of remaining alkylphenol in external solution is illustrated in Fig. 2, 3 and 4.

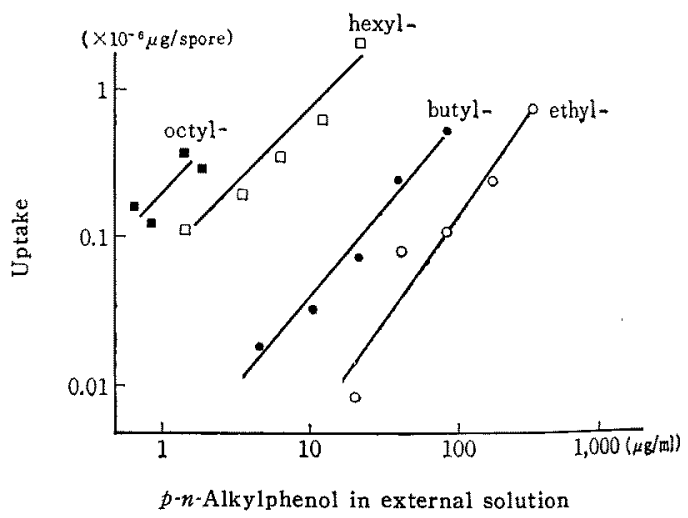

FIG. 2. Uptake of $p$-n-Alkylphenols by Spore of G. fujikuroi. 


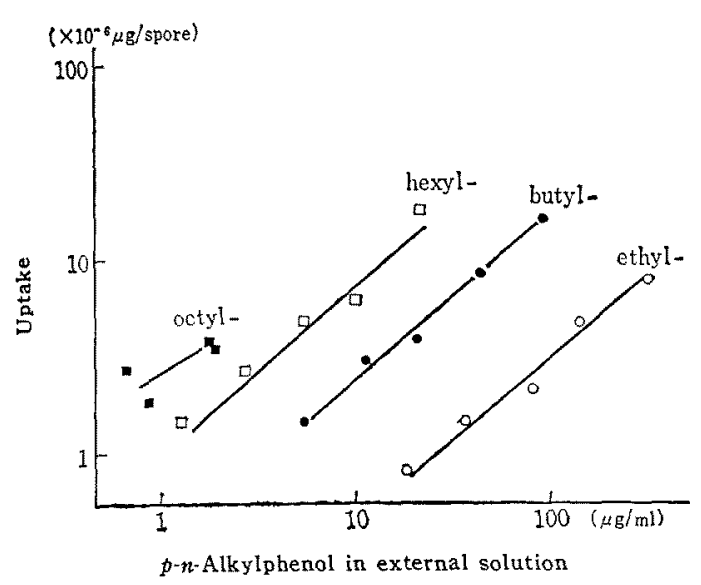

FIG. 3. Uptake of $p$ - $n$-Alkylphenols by Spore of $P$. oryzae.

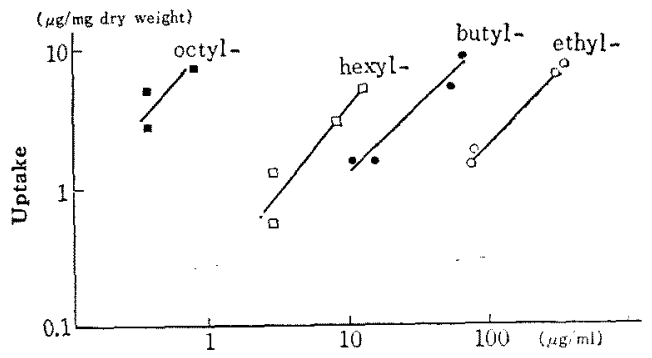

$p \cdot n$-Alkylphenol in external solution

FIG. 4. Uptake of $p$ - $n$-Alkylphenols by Mycelia of $P$. oryzae.

Uptake was raised with increase in length of alkyl group in all cases of spores of $P$. oryzae and $G$. fujikuroi, and mycelia of $P$. oryzae.

\section{Reversibility of Uptake}

Release of $p$-alkylphenol taken up by fungi into external aqueous phase was determined. Spores of $P$. oryzae and $G$. fujikuroi were treated with $p$-hexylphenol solution for sixty minutes as described above, and centrifuged. The spores were suspended in $\mathrm{m} / 15$ phosphate buffer, and the suspension was agitated and kept at $27.5^{\circ} \mathrm{C}$ for ninety minutes, then centrifuged. Concentration of $p$-hexylphenol in supernatant was determined.

If the process of uptake is reversible, release of the phenol can be calculated from Fig. 2, Fig. 3, and quantity of phenol initially taken up by spores. The values of release found and those calculated are compared in Table II. It shows that about $80 \%$ of the phenol was released from spores into external solution in ninety minutes according to the relationship illustrated in Fig. 2. and 3.

TABLE II. RELEASE OF $p$-HEXYLPHENOL FROM SPORES OF $P$. oryzae AND $G$. fujikuroi INTO Aqueous Phase

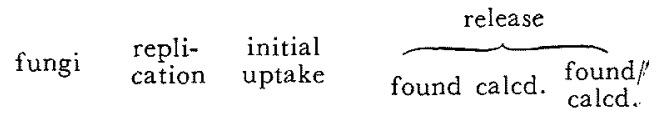

$$
\begin{aligned}
& \text { P. oryzae } \quad\left\{\begin{array}{ccccc}
\text { I } & 17.5 & 3.4 & 4.3 & 79 \\
\text { II } & 16.9 & 3.2 & 4.2 & 76 \\
\text { III } & 17.2 & 3.4 & 4.3 & 79
\end{array}\right. \\
& \text { G. fuji- (I } \quad 1.97 \quad 5.1 \quad 6.3 \quad 81
\end{aligned}
$$

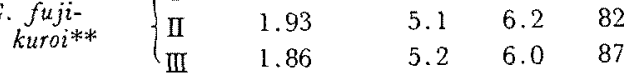

\section{DISCUSSION}

Uptake of $p$-n-alkylphenol by fungi seems to be governed by reversible physical process, and equilibrates with concentration of the phenol in external solution according to the

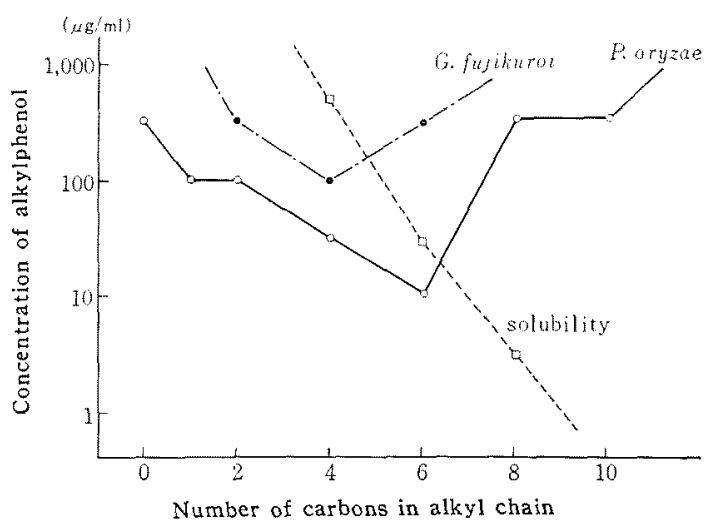

FIG. 5. Solubility and Minimum Growth-Inhibitory Concentration of $p$ - $n$-Alkylphenols. 
relationship illustrated in Fig. 2, 3 and 4. Uptake increases as the homologous series is ascended.

As the concentration of $p$-alkylphenol in external aqueous phase can not exceed its solubility, uptake of each homologue is limited to the value equilibrating with saturated concentration of the homologue in the aqueous phase. This limit of uptake decreases as the series ascends, because solubility decreases at a higher rate than the uptake increases.

The hypothesis is as follows: In homologous series of $p$-n-alkylphenols, fungicidal activity increases with increase in uptake as far as the limit of uptake is enough to inhibit growth of the fungi, but when the homologous series is ascended so far that the limit of uptake decreases to a value which is not enough to inhibit growth of fungi fungicidal activity falls off.

This hypothesis is assured at least partly by the relationship between minimum growthinhibitory concentration against the fungi," and solubility of the homologous series (Fig. 5). The minimum growth-inhibitory concentration curves decrease as the series ascends, but the solubility curve decreases at a higher rate, and crosses the minimum growth-inhibitory curves and cuts off the antifungal activity at these points.

Acknowledgement. The authors are indebted to Dr. K. Fukunaga and Dr. T. Suzuki of National Institute of Agricultural Sciences for their encouragement and guidance. 